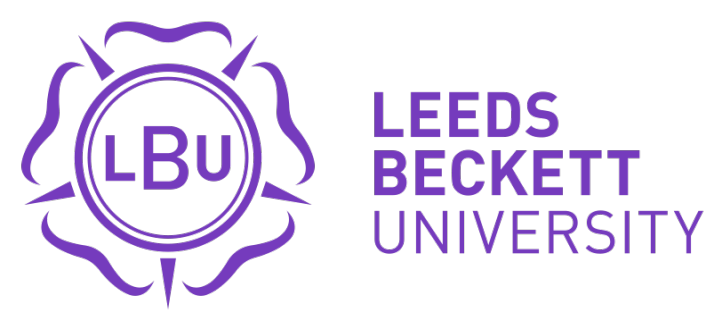

Citation:

Lofthouse, R and Hollweck, T (2021) Contextual coaching: levering and leading school improvement through collaborative professionalism. International Journal of Mentoring and Coaching in Education. ISSN 2046-6854 DOI: https://doi.org/10.1108/IJMCE-01-2021-0019

Link to Leeds Beckett Repository record:

https://eprints.leedsbeckett.ac.uk/id/eprint/7874/

Document Version:

Article (Accepted Version)

Creative Commons: Attribution-Noncommercial 4.0

The aim of the Leeds Beckett Repository is to provide open access to our research, as required by funder policies and permitted by publishers and copyright law.

The Leeds Beckett repository holds a wide range of publications, each of which has been checked for copyright and the relevant embargo period has been applied by the Research Services team.

We operate on a standard take-down policy. If you are the author or publisher of an output and you would like it removed from the repository, please contact us and we will investigate on a case-by-case basis.

Each thesis in the repository has been cleared where necessary by the author for third party copyright. If you would like a thesis to be removed from the repository or believe there is an issue with copyright, please contact us on openaccess@leedsbeckett.ac.uk and we will investigate on a case-by-case basis. 


\title{
Contextual coaching: levering and leading school improvement through collaborative professionalism
}

\begin{abstract}
$\underline{\text { Abstract }}$
Purpose

The research examines how contextual coaching (Gorrell and Hoover, 2009; Valentine, 2019) can act as a lever to build collaborative professionalism (Hargreaves and O'Connor, 2018) and lead to school improvement.

\section{Design/methodology/approach}

The multicase study (Stake, 2013) draws on two bespoke examples of contextual coaching in education and uses the 10 tenets of collaborative professionalism as a conceptual framework for its abductive analysis. Data from both cases were collected through interviews, focus groups and documentation.

\section{Findings}

The findings demonstrate that effective contextual coaching leads to conditions underpinning school improvement. Specifically, there are patterns of alignment with the 10 tenets of collaborative professionalism. Contextual coaching is founded on mutual dialogue, joint work, collective responsibility and collaborative inquiry. In more mature coaching programmes, collective autonomy, initiative and efficacy emerge. There is also evidence that opportunities exist for contextual coaching to be further aligned with the remaining tenets. The study offers insight into how school improvement can be realized by the development of staff capacity for teacher leadership through contextual coaching.

\section{Research limitations/implications}


The impact of coaching in education is enhanced by recognizing the importance of context and the value of iterative design and co-construction.

\section{Practical implications}

The principles of contextual coaching are generalizable, but models must be developed to be bespoke and to align with each setting. Collaborative professionalism offers a useful framework to better design and implement contextual coaching programmes.

\section{Originality/value}

The research introduces contextual coaching in education and how coaching can enhance collaborative professionalism in schools. 


\section{Contextual coaching: levering and leading school improvement through collaborative professionalism}

This paper contributes to the coaching in education literature by outlining and comparing two contextual coaching programmes - one in England and the other in Canada. In each case, a bespoke coaching approach was developed to meet the setting's unique school improvement challenges and opportunities. Using 'collaborative professionalism' (Campbell, 2021;

Hargreaves and O'Connor, 2018) as an analytic framework, this study examined how contextual coaching can act as a lever that leads to school improvement. Although each case was not originally designed using the collaborative professionalism (CP) framework, it offers powerful potential for coaching programme design and implementation.

Coaching in education is a highly effective professional development practice (Cordingley et al., 2015; Knight, 2017; Lofthouse, 2019) that improves student outcomes (Kraft and Blazar, 2017), teacher retention and wellbeing (Hollweck, 2019a), and collaborative cultures in schools (Lofthouse and Leat, 2013; Paterson and Munro, 2019). While there has been a professionalization of the mentoring role in education, which has included systematic training and increased regulation and accreditation, especially in the United Kingdom and United States (Moir and Bloom, 2003; Mullen, 2012), coaching in education is a relatively recent and unregulated initiative (Fletcher, 2012; van Nieuwerburgh, 2018). Bloom et al. (2005) define coaching to be 'the practice of providing deliberate support to another individual to help him/her to clarify and/or to achieve goals' (p. 5). Many models of coaching exist, each with protocols, principles and associated training and working practices. In business settings, the term 'contextual coaching' (Gorrell and Hoover, 2009; Valentine, 2019) has been introduced to recognize the significance of the relationship between context and coaching. In this paper, contextual coaching has been applied to the field of education to signal that there is no single 
'right way' to do coaching in education. Rather, effective coaching programmes are attuned to their setting and contribute to their context.

School improvement research highlights the importance of context, engaging the school community and changing culture in explaining school and system performance (Harris et al., 2015). At the heart of this work is a focus on teacher professional learning and collaboration (Campbell, 2017; Fullan and Hargreaves, 2016). As researchers and teacher educators, we were interested in both coaching and CP and the interplay between the two. Hargreaves and O'Connor (2018) describe CP as the solidarity of safe, supportive and trusting relationships for teachers combined with the solidity of robust and rigorous content, focus and structures that lead to 'stronger and better professional practice together' (p. 4). CP provides a useful framework of 10 tenets that outline ways in which teachers can collaborate more effectively.

Our multicase study (Stake, 2013) examines the extent to which contextual coaching may be congruent with the 10 tenets of $\mathrm{CP}$. The two cases offer insight into how school improvement can be realized by the development of teacher capacity, collaboration and leadership through coaching. Case 1 was teacher coaching for metacognitive pedagogies based in 10 primary schools in a Teaching School Alliance (TSA) in England, United Kingdom. Case 2 was coaching for induction and teacher development based in a secondary school in Western Quebec, Canada. The study answers Valentine's (2019) call for more empirical research on the relationship between context and coaching as well as the system-level factors that enhance coaching success.

\section{Coaching in education}

'Coaching is the art of facilitating the performance, learning and development of another' (Downey, 2003, p. 21). Coaching is underpinned by educational and psychological theories and research (Adams, 2015), being 'recognized as a powerful vehicle for increasing performance, 
achieving results and optimizing personal effectiveness' (Bachkirova et al., 2014, p.1). Grant (2013, p. 16) notes that while 'coaching' might imply a 'monolithic' activity, the term refers to a diversity of practices aimed at generating individual or organizational positive change.

Coaching is gaining popularity as a school improvement provision across international settings (Aguilar, 2020; Knight, 2017; van Nieuwerburgh et al., 2018). As coaching continues to grow in schools and systems, attempts to define coaching to clarify the coaching process and determine its impact on teaching and learning are ongoing (Hollweck, 2017; Kraft et al., 2018; Lofthouse, 2019; van Nieuwerburgh et al., 2018). However, there remain problems of weak definitional clarity (Hollweck, 2019a), under theorization (van Nieuwerburgh et al., 2018) and over-application of the term 'coaching' in schools (Bloom et al., 2005). There is also a call for more coaching practice to be anchored in research (Grant and O'Connor, 2019).

From the literature, we define coaching as a confidential and collaborative process through which coaches and coachees work together to reflect on current practices, as well as expand, refine, and build new skills. In both coaching and education practice there is an assumption that people can be supported to 'learn, grow and develop' (Campbell and van Nieuwerburgh, 2018). Coaches use powerful questioning, attentive and empathic listening, paraphrasing and summarizing, goal setting, and noticing (van Nieuwerburgh and Love, 2020). Through talk about teaching and learning, coaches and coachees can reflect, share ideas and teach one another; inquire into issues; or solve problems in the workplace. Coaching conversations are anchored in trust, safety, mutual respect, and curiosity (Hollweck, 2017; Lofthouse and Thomas, 2015).

Coaching success is increased with clear focus, defined roles, structure and a better understanding of how to give and receive constructive feedback (Hollweck, 2019b; Jarvis et al., 
2017; Knight, 2015). To become skilled, coaches need support, professional learning opportunities and time to gain experience (Hollweck, 2019a; Lofthouse and Rose, 2019; van Nieuwerburgh and Love, 2020). The coach's 'way of being' (Mezirow, 2009) also is an important element of effective coaching; 'the relationship between the coach and coachee must be one of partnership in the endeavour, of trust, of safety and of minimal pressure' (Whitmore, 2010, p. 20).

Researching mentoring and coaching in the voluntary sector, Cox (2003) acknowledged that context (e.g. personal relationships, cultures and subcultures, organizational mores) can produce functional complexities at a number of levels. In the field of executive and organizational coaching, 'contextual coaching' (Gorrell and Hoover, 2009; Valentine, 2019) is described as a process that emphasizes the importance of an organization's environment or context on its leadership development work (Gregory et al., 2009; Johns, 2006). For Valentine (2019), although contextual coaching has received renewed interest, there remains a dearth of extensive work on the relationship between context and coaching. He argues,

It is clear, then, that a knowledge of the system-level factors that inhibit or support coaching work, and the ability of an individual or group to sustain behavior change over time, would be useful in creating the conditions that are most conducive to accelerated organizational learning and development. (p. 94)

Similarly, in education, Munro (2017) highlights that 'when we come to implementing coaching in schools, context is everything' (p. 38). Coaching can also shape its educational context-for example, fostering enculturation and building a strong dialogic platform focused on teaching and learning (Proffitt, 2020). 
Like many school improvement initiatives, there is a danger in simply transplanting effective coaching programmes into new jurisdictions or organizations without considering the contextual and cultural features (Hargreaves and Skerrett, 2008). 'Whenever a new method, practice, or protocol surfaces in education, there is a common tendency to spread it too far and too fast, with little thought as to what else may be needed for the particular model or design to be effective in a sustainable way' (Hargreaves and O'Connor, 2018, p. 121). Thus, coaching has a mixed record of success, especially in settings where there are high levels of individual accountability (Lofthouse and Leat, 2013). In these schools, competing agendas and a 'performative environment' (Ball, 2003) in which teachers are compared, judged, measured and categorized can (un)consciously hijack coaching (Lofthouse and Leat, 2013) or coaching can be sidelined to teacher remediation and misconstrued to only be for struggling teachers (Rhodes and Beneicke, 2003).

\section{Collaborative professionalism}

Professional collaboration in schools has been shown to enhance student achievement, increase teacher retention and support system change (Campbell, 2017; Hargreaves, 2019; Hargreaves and Fullan, 2015; Johnson et al., 2012; Kraft et al., 2016); 'Collaboration is the new chorus line for innovation and improvement' (Hargreaves and O'Connor, 2018, p. 3). However, how teachers collaborate within a school is highly variable and not always effective nor desirable. In fact, Hargreaves (2019) argues that contrived collegiality and compliant collaboration often fail to yield the espoused benefits for schools and staff. For Campbell (2016), 'Collaboration_-like leadership_-is an attitude, behaviour and practice that needs to be learned, modelled, developed, demonstrated, tried out, improved and sustained' (p. 7). Building on this work, Hargreaves and O'Connor (2018) made the case for more consistent high-quality CP 
described as a deeper and more rigorous form of professional collaboration. Specifically, they examined how and how well teachers and other educators collaborate in order to guide schools and school systems to better and more deliberately design ways for educators to work together. The collaborative element of the term signals improved solidarity, trust, care, mutual respect and support amongst educators as they work together with collegiality to make a difference in the lives of the students in their school communities. The professionalism aspect champions the solidity of this challenging joint work. They offer this definition:

Collaborative professionalism is about how teachers and other educators transform teaching and learning together to work with all students to develop fulfilling lives of meaning, purpose, and success. It is organized in an evidence-informed, but not datadriven, way through rigorous planning, deep and sometimes demanding dialogue, candid but constructive feedback, and continuous collaborative inquiry. (Hargreaves and O’Connor, 2018, p. 4)

Ways to effectively build a culture of CP are outlined in the work of Campbell (2016, 2021), Sharratt (2016) and Fullan and Hargreaves (2016). CP is not simply about semantics, and nor does it refer to a specific programme, project or innovation that schools, professional organizations and educational systems can initiate and implement. Rather, it emerged from a comparison of five case studies of deliberately designed professional collaboration from Canada, Colombia, Hong Kong, Norway and the US Pacific Northwest. Specifically, CP outlines the frameworks and principles that describe a 'professional way of being' (Timperley et al., 2014) and is intended to help schools and school systems deliberately design effective ways for teachers and school staff to work together. 
For Hargreaves and O'Connor (2018), CP is a fundamental and necessary change needed in the global movement for educational innovation and improvement. Using, they highlight 10 key tenets:

1. Collective autonomy: Teachers' professional judgement is valued, and they have relative independence from top-down bureaucratic authority, but less independence from each other.

2. Collective efficacy: Teachers believe that together they can make a difference to the students they teach, no matter what.

3. Collaborative inquiry: Teachers routinely explore problems, issues or differences of practice together and make evidence-informed decisions to improve or transform what they are doing.

4. Collective responsibility: Teachers develop a mutual and moral obligation to help each other to become better in order to serve all students in the school community.

5. Collective initiative: There are fewer initiatives in schools, but more initiative by communities of strong individuals committed to learning with and from each other.

6. Mutual dialogue: Teachers' collaborative work is characterized by meaningful, respectful and constructive dialogue and feedback.

7. Joint work: Teachers engage in thoughtful and productive work to examine and improve professional practice facilitated by structures, tools, and protocols.

8. Common meaning and purpose: Teachers articulate and advance a common purpose that is greater than test scores or even academic achievement and aims to 
make a difference in the lives of young people so they can thrive and flourish as whole human beings.

9. Collaboration with students: Not only are students the focus of the collaborative work, but they are actively engaged with their teachers in constructing educational change together.

10. Big picture thinking for all: Teachers and school staff as well as school and system leaders see, live and create the big picture together.

In the deliberate design and implementation of $\mathrm{CP}$, it is critical to consider the role of context. Hargreaves and O'Connor (2018) highlight four contextual and cultural factors for effective implementation of collaborative designs leading to school or system improvement. These factors are referred to as the four $B s$ and are described as that which comes before, betwixt, between and beyond the $\mathrm{CP}$ design. Each is explored through key questions:

- What came before the model of CP existed?

- What other kinds of collaboration exist betwixt or alongside the model in question in the school and in the distinctive culture of the whole society?

- What support does the system provide beside the specific collaborative design in government grants, in official allocations of time for collaboration or in wider professional networks?

- What connections does any specific design have to collaborative ideas and actions beyond the school, in overseas schools, in international research, in online interaction or elsewhere?

The four Bs of CP help school and system leaders 'better understand and also activate the context and cultures that precede, succeed, and surround it [initiatives such as coaching]' (p. 
121). Ultimately, the implementation and sustainability of any school improvement initiative requires trust across the school and school system, positive professional relationships, a shared understanding of the purpose and process and, of course, sufficient resources, such as time, support and funding (Campbell, 2017; Hargreaves and Fullan, 2015).

\section{The multicase study approach}

\section{The multicase study}

'Qualitative case study was developed to study the experience of real cases operating in real situations' (Stake, 2013, p. 3). Multicase study research uses cases that are examined separately but are similar in some ways. Stake (2013) calls this collective condition in multicase study research a quintain: 'We study what is similar and different about the cases in order to understand the quintain better' (p. 6). In this study, the quintain was bespoke contextual coaching programmes located within a school (Case 2) or network of schools (Case 1). This study emerged through conversations between the co-authors which related to the commonalities between the two cases that were noted and their resonance with $\mathrm{CP}$.

The purpose of this study is therefore to describe and compare two bespoke coaching programmes. Table 1 provides details of each case of contextual coaching. In both cases, one of the intended objectives of the coaching programmes was school improvement. The expectation was that this would be leveraged through teachers' professional development leading to enhanced teaching, learning and achievement. The programmes can be described as 'contextual coaching' because the coaching practices were developed as part of bespoke approaches designed to meet the specific challenges of the schools' contexts and because the coaching was situated within broader professional learning provision. The multicase study approach enables a consideration of the ways in which contextual coaching in education is congruent with 
Hargreaves and O'Connor's (2018) conceptual framework of CP and can thus contribute to

school improvement.

\begin{tabular}{|c|c|c|}
\hline $\begin{array}{l}\text { Coaching } \\
\text { programme }\end{array}$ & $\begin{array}{l}\text { Case } 1 \\
\text { Teacher coaching for metacognitive } \\
\text { pedagogies (maths focus) }\end{array}$ & $\begin{array}{l}\text { Case } 2 \\
\text { Teacher coaching for professional learning } \\
\text { (induction, mentoring and coaching) }\end{array}$ \\
\hline Location & North Yorkshire, England & Western Quebec, Canada \\
\hline $\begin{array}{l}\text { Acronyms used } \\
\text { for each case }\end{array}$ & $\begin{array}{ll} & \text { TSA: Teaching School Alliance } \\
- & \text { SSIF: Strategic School Improvement Fund } \\
- & \text { LP: Lead Practitioners (working as coaches) } \\
\text { - } & \text { LT: Lead Teacher } \\
\end{array}$ & $\begin{array}{ll} & \text { TIP: Teacher Induction Programme } \\
\text { - } & \text { TF: Teaching Fellow (teachers in their first two } \\
& \text { years of employment in the school board) } \\
\text { - } \quad \text { LC: Lead Coach }\end{array}$ \\
\hline $\begin{array}{l}\text { Schools' } \\
\text { contexts }\end{array}$ & $\begin{array}{ll}- & \text { Ten primary schools in a TSA } \\
\text { - } & \text { Rural settings with significant numbers of } \\
\text { children from military families. }\end{array}$ & $\begin{array}{l}\text { - One large secondary school with two campuses } \\
\text { (junior high school and high school) } \\
\text { - Urban mixed-socioeconomic setting }\end{array}$ \\
\hline $\begin{array}{l}\text { Context and } \\
\text { objectives of } \\
\text { contextual } \\
\text { coaching }\end{array}$ & $\begin{array}{l}\text { Coaching was part of a government funded SSIF } \\
\text { project Teachers to gain greater expertise for } \\
\text { teaching maths through metacognitive } \\
\text { pedagogies, to raise pupil attainment. } \\
\text { Teachers to be able to subsequently lead } \\
\text { development in school. }\end{array}$ & 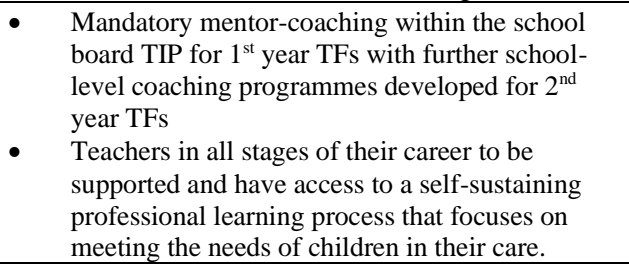 \\
\hline $\begin{array}{l}\text { Schedule of } \\
\text { coaching and } \\
\text { data collection }\end{array}$ & $\begin{array}{l}\text { - } \\
\text { SSIF project ran for five terms from September } \\
\text { - } \quad \text { LPs worked with LTs in each school using } \\
\text { contextual coaching from January } 2018 \text {. } \\
\text { - } \quad \text { Evaluation data collected throughout SSIF project }\end{array}$ & $\begin{array}{l}\text { - TIP coaching for Year } 1 \text { TFs introduced in } 2011 \\
\text { by the school board, TIP coaching for Year } 2 \text { TFs } \\
\text { introduced in } 2017 \text { by the school with additional } \\
\text { peer coaching started in } 2015 \text {. } \\
\text { - } \quad \text { Data collected via a study visit in October } 2018 \text {. }\end{array}$ \\
\hline $\begin{array}{l}\text { Coaches and } \\
\text { coachees }\end{array}$ & $\begin{array}{l}\text { One SSIF designated LT per school was coached } \\
\text { by LPs. The LTs were selected by senior leaders. } \\
\text { LPs were three experienced teachers newly } \\
\text { appointed as lead practitioners for the SSIF } \\
\text { project. } \\
\text { Each LP maintained a coaching relationship with } \\
\text { three or four schools over project. }\end{array}$ & $\begin{array}{l}\text { - Two LCs were full-time teachers, selected by the } \\
\text { school principal as in-school support for coaches. } \\
\text { The fifteen TIP coaches were full-time } \\
\text { experienced teachers in the school who worked } \\
\text { with seven Year } 1 \text { TIP TFs and six Year } 2 \text { TIP } \\
\text { TFs. } \\
\text { - The } 16 \text { peer coaches were full-time experienced } \\
\text { teachers. }\end{array}$ \\
\hline $\begin{array}{l}\text { Outline of } \\
\text { coaching } \\
\text { approach }\end{array}$ & $\begin{array}{l}\text { Specialised contextual coaching occurred } \\
\text { regularly during scheduled visits by coaches to } \\
\text { each school. } \\
\text { Coaches worked with LTs using modelling of } \\
\text { teaching, joint planning, co-teaching and } \\
\text { debriefing. }\end{array}$ & $\begin{array}{l}\text { - The TIP used a contextual coaching model that } \\
\text { included goal setting, reciprocal classroom } \\
\text { observations and debriefing, preparation of a } \\
\text { reflective record, co-planning, and modelling of } \\
\text { instructional strategies. }\end{array}$ \\
\hline $\begin{array}{l}\text { Funding and } \\
\text { time allocation } \\
\text { for coaching }\end{array}$ & $\begin{array}{l}\text { - SSIF project budget paid salaries of LPs and } \\
\text { release time for LTs to work with coaches and } \\
\text { attend network meetings. }\end{array}$ & $\begin{array}{l}\text { The TIP was funded by the school board. All } \\
\text { professional learning for coaches was run by TIP } \\
\text { consultants. Funds cover release time for Year } 1 \\
\text { TIP TFs to work together. } \\
\text { The Year } 2 \text { TIP coaching and the peer coaching } \\
\text { were fully funded by the school. All coaching, } \\
\text { classroom observations and debriefs happened } \\
\text { based on teachers' availability. }\end{array}$ \\
\hline
\end{tabular}

Table 1. The characteristics of the two contextual coaching programmes

\section{Case 1 method}

Case 1 was an evaluation of a Strategic School Improvement Fund (SSIF) project funded

by the Department for Education (DfE) in England with a coaching programme in 10 North 
Yorkshire primary schools at its core. The project evaluation was conducted from 2017 to 2019 by one of the co-authors. The evaluation used a 'theory of change' (ToC) methodology (Laing and Todd, 2015) that was individualized in each of the 10 schools and co-constructed with the lead practitioners (coaches). ToC explained the process of change by defining and outlining the initiative's long-term goals and mapping it backward. This method allowed an iterative evaluation of the coaching approach and a recognition of the role of the context (e.g. policy, school and community contexts) in its success of achieving change. Data for Case 1 were collected through field notes, interviews and focus groups with coaches, lead teachers (LTs) and the programme director, and pupil progress information provided by each school. All interviews and focus groups were audio recorded for transcription. The final evaluation was a DfE funding requirement, and results were published in Lofthouse and Rose (2019) and disseminated at professional conferences.

\section{Case 2 method}

Case 2 was a study visit to a large secondary school in Gatineau, Quebec (Canada), undertaken in 2018 by the co-authors and funded by the Universities Council for the Education of Teachers (UCET) in the United Kingdom. The research also contributed to one co-author's doctoral research project, which was a qualitative case study (Yin, 2014) of the Western Quebec School Board's Teacher Induction Program (TIP). Data for Case 2 were collected through recorded interviews and focus groups with the school leadership team (one principal and two vice-principals), coaches and coachees. Extensive notes were taken by both co-authors during the study visit, and verbatim transcripts were made of all audio recordings. Findings were disseminated via conferences, a UCET study visit report, blog post (Lofthouse, 2018) and a professional magazine (Hollweck, 2020). 


\section{Abductive analysis}

Abductive analysis (Tavory and Timmermans, 2014) was used to examine the evidence from both Case 1 and Case 2 with and against the 10 tenets of CP. Described as an alternative to inductive and deductive processes, abductive analysis is a 'creative inferential process' (Tavory and Timmermans, 2014, p. 5) that produces new theoretical hypotheses. Researchers generate theoretical insights from unexpected findings by working iteratively with and against research evidence, the conceptual frameworks and theories (Chew, 2020). Three criteria inform the success of abductive analysis: fit of evidence to theoretical claims, 'plausibility' of meaning making through comparison with existing theories and 'relevance' from impact to research field and to relevant communities (Earl Rinehart, 2020; Timmermans and Tavory, 2012).

Data were collected between 2017 and 2019, and the multicase abductive analysis was conducted in 2020. Rather than be seen as a limitation, as co-authors we found that time away from the original data and the collaborative abductive analysis suited and strengthened the multicase study approach. Over six months, we took time to revisit and work with the research evidence from the two cases in order to familiarize and defamiliarize ourselves (Tavory and Timmermans, 2014). At regular (bi-weekly) intervals, we would convene using an online platform to share notes, initial codes and categories (Saldaña, 2015) as well as emerging ideas and then go back to rethink, reword and reorganize. Similar to the 'framework method' (Ritchie and Spencer, 1994) a chart with the 10 CP tenets listed horizontally and the two cases in separate but aligned columns was used to note key ideas, participant quotes and strength of association (see 'Findings' section). Unexpected findings were recorded and grouped into categories representing similar phenomena and ideas. All categories and further analytic conclusions from the data were discussed and finalized and incorporated into the discussion. 


\section{Findings}

\section{Before and betwixt; the contextual nature of the cases of coaching}

The contextual nature of the two coaching cases can be illustrated through the 'before' and 'betwixt' CP questions noted earlier in the paper.

Case 1: The English example of teacher coaching for metacognitive pedagogies was developed within a TSA and funded by the DfE. Teaching Schools were first established in 2011 and were part of a drive towards a policy ambition of a 'school-led self-improving system' (see Greany and Higham, 2018). Each TSA was expected to lead 'school improvement initiatives based on school partnerships' (Gu et al., 2015, p. 17). SSIF grants supported TSAs to focus on particular improvement needs identified through national performance data and use approaches considered to be evidence-informed. In this case, the SSIF project involved 10 primary schools, some of which had been partners in previous collaborative projects. The funds were awarded for three key reasons. First, the 10 schools served military communities where children typically underperformed. Second, the project prioritized mathematics which is considered a learning priority and is used as a key indicator of school performance. Third, it focused on pupil metacognition and self-regulation which is considered 'high impact for very low cost, based on extensive evidence' (Quigley et al., 2018, p. 4). A model described as 'contextual specialist coaching' (Lofthouse and Rose, 2019, p. 24) was developed alongside a wider SSIF project infrastructure which evolved over the duration of the project. Three lead practitioners were employed and acted as the coaches for an LT in each of the 10 schools. The SSIF project also funded pedagogical resources, staff training and a virtual platform that could be used to share project materials, teacher reflections and examples of pupils' work. These provided a common foundation and experience for teachers engaged in the project. There was also a steering group 
which consisted of headteachers and deputy headteachers from the schools, and external advisers.

Case 2: The Canadian example of coaching for induction and teacher development was developed and implemented by the Western Quebec School Board (WQSB), an Englishlanguage school district in a mainly French-speaking province. The WQSB's TIP was first established in 2010 as a response to the challenge in the school district in attracting and retaining effective new teachers, especially in rural and northern schools. All teachers new to the districtcalled teaching fellows (TFs)—-were paired in their first year with experienced teachers who supported them as mentor-coaches (MCs). Case 2 focused on a secondary school where there was initial resistance to the TIP. Over time, school leaders and staff saw how the TIP could be useful to support both new and experienced teachers in their school and thus developed more bespoke coaching provision for TFs in their second year. This peer coaching model complemented another coaching programme implemented through an external partnership with the OLEVI Alliance in England. Lead coaches (LCs) in both programmes worked together to establish monthly informal 'coaches' breakfasts' which gave all coaches an opportunity to meet before school to share experiences, ideas and best practice.

The contextual coaching in each case was thus a response to the policy challenges and opportunities in their specific settings. The approaches were adapted over time, with changes largely being the result of co-construction between coaches and/or coachees in the contexts of the schools. Analysis of the cases of coaching in relation to the $\mathrm{CP}$ tenets revealed the significance of the contextualization of the coaching. 


\section{The 10 tenets of $\mathrm{CP}$ in the cases of contextual coaching}

The contextual coaching cases in this study were not designed according to $\mathrm{CP}$ principles, and data were not specifically collected to provide evidence of CP tenets as outcomes. However, our abductive analysis enabled a judgement of the fit of contextual coaching with CP. The multicase study findings provide evidence of the degree of congruence between $\mathrm{CP}$ and the two cases. The patterns of alignment and divergence between the two cases allowed us to develop plausible conclusions, which help to demonstrate the potential of contextual coaching as a lever for school improvement. Findings are given in three parts:

- CP tenets as foundations of contextual coaching,

- $\mathrm{CP}$ tenets which strengthened over time through contextual coaching, and

- $\mathrm{CP}$ tenets with the potential to further develop contextual coaching for school improvement.

These patterns are detected across the two temporal dimensions. In each case, there is the coaching time span from planning through co-construction to outcomes, and between the two cases there is the significance of the more sustained and mature contextual coaching of Case 2 . Figure 1 provides an overview of the analysis.

\section{CP tenets as foundations of contextual coaching: mutual dialogue, joint work, collaborative inquiry and collective responsibility}

Four CP tenets had the strongest alignment across the planning, co-construction and outcomes stages of both contextual coaching cases. They form consistent patterns between the two cases, as shown in Figure 1. We consider these tenets to be foundational to contextual coaching because all four are fundamental in coaching. 


\begin{tabular}{|c|c|c|c|c|c|}
\hline $\begin{array}{c}\text { Tenet of } \\
\text { Collaborative } \\
\text { Professionalism } \\
\text { (CP) }\end{array}$ & $\begin{array}{l}\text { Contextua } \\
\text { l Coaching } \\
\text { (CC) Case }\end{array}$ & $\begin{array}{c}\text { Evidence for } \\
\text { tenet at } \\
\text { planning stage } \\
\text { of contextual } \\
\text { coaching }\end{array}$ & $\begin{array}{c}\text { Evidence of } \\
\text { tenet in co- } \\
\text { construction of } \\
\text { contextual } \\
\text { coaching stage }\end{array}$ & $\begin{array}{l}\text { Evidence of } \\
\text { tenet in } \\
\text { outcomes of } \\
\text { contextual } \\
\text { coaching }\end{array}$ & Analysis \\
\hline \multirow{2}{*}{$\begin{array}{l}\text { Collective } \\
\text { autonomy }\end{array}$} & 1 & & & & \multirow[t]{2}{*}{$\mathbf{S}$} \\
\hline & 2 & & & & \\
\hline \multirow{2}{*}{ Collective efficacy } & 1 & & & & \multirow[t]{2}{*}{$\mathbf{S}$} \\
\hline & 2 & & & & \\
\hline \multirow{2}{*}{$\begin{array}{c}\text { Collaborative } \\
\text { inquiry }\end{array}$} & 1 & & & & \multirow[t]{2}{*}{$\mathbf{F}$} \\
\hline & 2 & & & & \\
\hline \multirow{2}{*}{$\begin{array}{c}\text { Collective } \\
\text { responsibility }\end{array}$} & 1 & & & & \multirow[t]{2}{*}{$\mathbf{F}$} \\
\hline & 2 & & & & \\
\hline \multirow[t]{2}{*}{ Collective initiative } & 1 & & & & \multirow[t]{2}{*}{$\mathbf{S}$} \\
\hline & 2 & & & & \\
\hline \multirow[t]{2}{*}{ Mutual dialogue } & 1 & & & & \multirow[t]{2}{*}{$\mathbf{F}$} \\
\hline & 2 & & & & \\
\hline \multirow[t]{2}{*}{ Joint work } & 1 & & & & \multirow[t]{2}{*}{$\mathbf{F}$} \\
\hline & 2 & & & & \\
\hline \multirow{2}{*}{$\begin{array}{c}\text { Common meaning } \\
\& \text { purpose }\end{array}$} & 1 & & & & \multirow[t]{2}{*}{$\mathbf{P}$} \\
\hline & 2 & & & & \\
\hline \multirow{2}{*}{$\begin{array}{c}\text { Collaboration with } \\
\text { students }\end{array}$} & 1 & & & & \multirow[t]{2}{*}{$\mathbf{P}$} \\
\hline & 2 & & & & \\
\hline \multirow{2}{*}{$\begin{array}{l}\text { Big picture thinking } \\
\text { for all }\end{array}$} & 1 & & & & \multirow[t]{2}{*}{$\mathbf{P}$} \\
\hline & 2 & & & & \\
\hline
\end{tabular}

Key

\begin{tabular}{l|l|l}
$\begin{array}{l}\text { No evidence of alignment } \\
\text { between CP tenet and } \\
\text { characteristics of the case of } \\
\begin{array}{l}\text { CC at the planning stage, } \\
\text { through co-construction and/or } \\
\text { in outcomes. }\end{array}\end{array}$ & $\begin{array}{l}\text { Moderate evidence of } \\
\text { alignment between CP tenet } \\
\text { and characteristics of the case } \\
\text { of CC at the planning stage, } \\
\text { through co-construction and/or } \\
\text { in outcomes. }\end{array}$ & $\begin{array}{l}\text { Strong evidence of alignment } \\
\text { between CP tenet and } \\
\text { characteristics of the case of } \\
\text { CC at the planning stage, } \\
\text { through co-construction and/or } \\
\text { in outcomes. }\end{array}$ \\
\hline
\end{tabular}

\begin{tabular}{|l|l|l|l|l|l|}
\hline $\mathbf{F}$ & $\begin{array}{l}\text { Four CP tenets which are } \\
\text { the foundation for CC. } \\
\text { These tenets describe the } \\
\text { core characteristics of } \\
\text { coaching in education } \\
\text { settings. There was } \\
\text { evidence of the presence } \\
\text { of these CP tenets in } \\
\text { original planning of both } \\
\text { coaching programmes. }\end{array}$ & $\mathbf{S}$ & $\begin{array}{l}\text { Three CP tenets which } \\
\text { are strengthened over } \\
\text { time through CC from } \\
\text { planning to co- } \\
\text { construction to outcomes } \\
\text { stage in both cases. The } \\
\text { stronger overall } \\
\text { alignment in Case 2 than } \\
\text { Case 1 are evidence for } \\
\text { impact of more sustained } \\
\text { CC on CP. }\end{array}$ & $\mathbf{P}$ & $\begin{array}{l}\text { Three CP tenets which } \\
\text { were not planned into the } \\
\text { CC design. They } \\
\text { followed the same pattern } \\
\text { of emergence during co- } \\
\text { construction but did not } \\
\text { substantially strengthen } \\
\text { further as outcomes. } \\
\text { These CP tenets have the } \\
\text { potential to further } \\
\text { develop CC for school } \\
\text { improvement. }\end{array}$ \\
\hline
\end{tabular}

Figure 1. Abductive analysis summary 
In Case 1, joint work included the coaches working with LTs in 10 alliance schools to support them to develop pedagogic practices over a sustained period (about two years).

Collaborative inquiry between the coaches and LTs meant a focus on developing pedagogy was sustained, with issues and opportunities identified and new approaches trialled. Student engagement and progress data were collected leading to shared understanding. The coaches engaged in mutual dialogue to develop and continually review their practices, and their coaching dialogue with LTs focused on co-planning and offering feedback. The LTs developed their collective responsibility through a growing capacity to support their colleagues which was enhanced through network meetings and cluster observations enabled by the SSIF funding.

In Case 2, the TIP coaches worked with TFs over a year to support them to set goals, build their Reflective Record and improve classroom practice. This joint work included coplanning, co-teaching and reciprocal observations and feedback. More broadly, coaches worked on goal setting and reciprocal observations and feedback. Their coaching conversations (mutual dialogue) were confidential and non-evaluative. Coaches used coaching protocols, such as the GROW model (Whitmore, 2010), and the impact cycle (Knight, 2017). Coaching aimed to improve teaching through collaborative inquiry in action-setting goals based on teacher competencies and reciprocal classroom observations. Collective responsibility resulted in more classrooms being open to colleagues to visit. Coaches developed enhanced capacity to support colleagues in different career stages. They reported a shared responsibility for all students in the school community.

Thus, mutual dialogue and joint work were consistently planned for in both cases, with coaches and coachees focused on developing teaching practices. In addition, the coaching 
created conditions for context-specific forms of collaborative inquiry. The interrelationship between these tenets was critical in sustaining practices focused on improvement:

We have a relationship that has been built. There is an understanding. It has been built on a platform of coaching — observing and questioning. (Case 2, Coach)

We are all in this to be pushed. We also want to push each other. I would be really disappointed if my coach didn't come up with a great question for me. (Case 2, LC)

What's been nice for me is having a professional conversation. It's a continuous, professional discussion with someone who is only looking at metacognition ... a proper professional conversation with somebody who actually knows what they are talking about and can actually say: 'well I don't know that, but I'll find out for you or I'll look into that'. (Case 1, SSIF LT)

In both cases, coaches and teachers were recognized and valued as active learners. In the original conceptualization of $\mathrm{CP}$, the focus of collective responsibility is for children and young people as learners, but our cases of coaching provide evidence that this responsibility was applied to colleagues and their learning. The sustained mutual dialogue and joint work built a more holistic understanding of teaching and helped teachers to feel a greater responsibility to each other.

I find that when I come to these meetings, I always go back with tons of new stuff to remind me to put into lesson plans, to add to staff meetings. They energize you. They motivate you again to keep it going. It has motivated us to get on and move it forward even for others. (Case 1, SSIF LT) 
I am learning the culture of the school through my coach. I see everyone as human beings first and who they are and what is important to them as a community. This is more than a school; this is a community. It builds a community by showing care. (Case 2, TIP TF)

Collective responsibility was also evident in both cases through an emerging commitment of participants to new leadership roles. In Case 1, there were nine LTs active throughout the duration of the SSIF project. As the project ended, all of them had applied to become specialist leaders in education or anticipated applying when their personal circumstances allowed.

Additionally, two of the LTs became more actively involved in whole-school planning for school improvement. In Case 2 two, participants had volunteered to take on the leadership of coaching in their school as LCs. In both cases, there was also evidence of the significance of ensuring that coaches were supported to take care of each other and take collective responsibility for their development as coaches. In Case 2, this was evidenced by the introduction of coaches' breakfasts.

CP tenets which strengthened over time through contextual coaching: collective autonomy, collective initiative and collective efficacy

There were three tenets of $\mathrm{CP}$ which existed at different levels at the planning stages of the two cases and which strengthened during co-construction. These were collective autonomy, collective initiative and collective efficacy. Case 2 had the strongest overall alignment with these three tenets. This pattern is shown in Figure 1.

Case 1 was initially tightly framed through the SSIF funding criteria and the project steering group. However, the collective autonomy of both the coaches and LTs grew over the duration of the project, with both groups being afforded more opportunities to work and learn together and the role of the steering group becoming diminished. This led to the coaches and LTs 
taking more collective initiative over time, developing an understanding of what activities would enable progress towards the goals and how the defined project framing could be fine-tuned to the development needs of the LTs and to each school. The coaches built significant collective efficacy and developed a belief in the value of their emerging coaching practices. Network meetings and cluster observations helped LTs to develop shared confidence and belief in their metacognitive pedagogic practices as the project evolved.

In Case 2, the coaching evolved over a decade. It drew on the experiences and collective autonomy of several cohorts of coaches and coachees, with key outcomes of extending and enhancing the original coaching provision to develop further opportunities in the school. Collective initiative existed as coaches and coachees regularly met based on their own schedules. The coaches' breakfasts were developed and facilitated by the LCs; attendance was voluntary. TIP coaches and TFs worked together to support the students in their joint care. Increased collective efficacy was also evidenced as other coaches collaborated across divisions and levels, recognizing that instructional strategies which enhance classroom practice in one setting could also benefit another.

Case 2 can be considered a more mature model of contextual coaching than Case 1, being sustained over 10 years and not being specifically tied to a time-limited funded project.

Over 10 years ... not just the work of the teachers, but the nature of the way the school works has changed. Same kids, but our system has changed. We have all grown. We focus on teaching and learning in this school. I find being part of the school that I learn, and we are all on that continuum. (Case 2, Principal) 
The coaches in Case 1 stated that their original motto of 'Think big; Start small' had been an important principle of their work with LTs emphasizing that embedding new pedagogic approaches takes time,

for they [the teachers] will go into leadership roles and think, change does not happen overnight. They are going to have that mind-set and that's a fantastic place to be in moving forward and moving schools forward. (Case 1, SSIF Coach)

Hence, the findings suggest that developing contextual coaching over a sustained period strengthens the opportunities for teachers to make decisions and take action together, with less influence from school leadership or hierarchical structures.

A shared phenomenon in both cases was that collective autonomy as suggested below.

You're not just being left on your own to flounder with something totally new, and you're not trying to find all the information all on your own. You're doing it with somebody. (Case 1, SSIF LT)

There is a breakdown of the silos and the climate of the administration. We are often collaborating, and it is clear that in the staff meeting - there is an effort to mix people up-there is focusing on reflection. (Case 2, Coach)

This tenet of collective autonomy was not present in the initial design of Case 1 whereas it had existed to a moderate extent in Case 2. In both cases it was co-constructed through adaptations to the coaching programmes.

In both cases, the coaching programmes were initiated by school and system leadership; however, collective initiative of the participants grew over time. As the original coaching 
programmes were adapted through co-construction between coaches, teachers and school leaders, their contextualization was strengthened. In Case 2, this was more apparent, and participants reported how coaching had become infused in other initiatives, as well.

We are taking the [coaching] model and transplanting it onto a different initiative with people from a different school. (Case 2, LC)

Although coaching programmes can promote collective efficacy in their design, it is not an automatic outcome. Rather, it results from the sustained experience of working successfully with colleagues, and can emerge, be consolidated or enhanced through contextual coaching. The confidence that this can give teachers in their own and each other's practices is illustrated here.

When I wake up in the morning, I have no stress. If I have a problem with some student ... I am not afraid to explain what is going on and ask for help. It is a family ... This is great. And this is what I love. (Case 2, TIP Coach)

\section{CP tenets with the potential to further develop contextual coaching for school improvement: common meaning and purpose, big picture thinking for all and collaborating with students}

The two contextual coaching cases align with all 10 tenets of $\mathrm{CP}$; however, there are three tenets, common meaning and purpose, big picture thinking for all and collaborating with students, where this is limited. The patterns between the two coaching cases for these tenets are similar, and there is limited change over time (see Figure 1). It is possible that these three tenets provide indications of how contextual coaching programmes could be differently designed or adapted to relate more strongly to the educational contexts within which they are situated. 
Analysis of the two cases illustrate that students' learning and wellbeing was primarily situated as the subject of teachers' work together but that collaboration with students was relatively underdeveloped within the contextual coaching programmes. Some opportunities for teachers to gain and articulate common meaning and purpose beyond student attainment were developed in both coaching programmes, although they were not explicit in the original coaching plans. In Case 1, the clear framing of the SSIF project provided an initial pedagogic focus (metacognition in maths) with the projection that this would improve academic results. However, as described below, the LTs developed an expanded understanding of the significance of metacognition, in part by recognizing how it was a foundation of good teaching across the curriculum.

There are major links between [pupil premium objectives] and metacognition. It's very much the way our school wants to go now to improve outcomes for these pupils. (Case 1, SSIF LT)

It [metacognition] is beautifully aligned to science. You can do it everywhere. (Case 1, SSIF LT)

Across both cases, the common meaning and purpose was gained most strongly in relation to how the coaches and coachees conceptualized their settings as being places for professional learning, as illustrated below.

There is a culture here, you can feel it in the air. (Case 2, TIP TF)

There is not one teacher in this building NOW (it was different before) who will say no if you want to go in and observe. (Case 2, Principal)

Similarly, big picture thinking for all was not present in the design of either case, but it started to emerge over time. In Case 1, for example, continuing professional development was designed for 
all school staff to encourage them to take key project ideas and co-develop their own practices associated with them. The coaches in Case 1 and LCs in Case 2 recognized substantive and potential relationships between the coaching programme and other school and system initiatives. Big picture awareness in Case 1 led to a sense of realism of the opportunities and constraints of the SSIF model for sustaining school improvement. In Case 2, since the LCs had been participants in all coaching programmes, they developed a more coherent understanding of teacher support and development.

\section{Discussion}

Effective teacher professional development and collaboration can lead to school improvement (Campbell, 2017; Fullan and Hargreaves, 2016; Hargreaves, 2019). Coaching in schools can support teacher learning and development (Hollweck, 2019a; Lofthouse, 2019), increase student outcomes through improved teacher practice (Kraft and Blazar, 2017) and lead to more collaborative school cultures (van Nieuwerburgh et al., 2018). Both coaching programmes were effective levers for school improvement with each case reporting enhanced teacher learning and an improved collaborative culture (Hollweck, 2019b; Lofthouse and Rose, 2019). This multicase study aimed to explore the relationship between coaching and school improvement further by using CP as its conceptual lens. Our abductive analysis led us to develop five key themes: deliberate yet flexible designs and structures of support, responsiveness to school culture and context, a shared purpose and understanding, teacher autonomy and leadership, and long-term commitment and resources.

\section{Deliberate yet flexible designs and structures of support}

The coaching design in each case was initially selected, introduced and resourced by external sources. School leaders acted as gatekeepers by championing the coaching in varying 
degrees, deploying staff and steering the programmes; however, it was the participants who made it flourish. Clear objectives, deliberate and supportive structures, available resources and a common purpose created the conditions for improved classroom practice. Neither case focused on fidelity to a particular coaching model, process or approach. Rather, the design was flexible enough to make space for meaningful co-construction with coaches and attunement to the setting. It was this self-determining and iterative element of contextual coaching that increased its sustainability and enabled CP to flourish across and beyond the active coaching cohorts. As CP flourished, it was the professionals involved who began as a collective to take responsibility for shaping the coaching structure and design.

\section{Responsiveness to school culture and context}

Hargreaves and O'Connor (2018) warn against transplanting one effective collaborative model into another context in the hope of replicating success: 'Reform is like bad fruit: It never travels well' (p. 131). Effective and deliberate CP designs like contextual coaching are embedded in the wider and longer term cultures of schools and their systems. Thus, coaching programmes cannot simply be inserted into schools and expected to work in isolation; they must be part of a broader programme design so that the intelligence gathered through coaching can feed back to the wider system and vice versa. Understanding contextual coaching inside and alongside other initiatives — what is before, beside, betwixt, and beyond (the four Bs) — is necessary for its overall success. Ultimately, contextual coaching is iterative; it shifts and changes over time in relation to its context, and the context changes in relation to the coaching (Cox, 2003; Valentine, 2019). 


\section{A shared purpose and understanding}

Contextual coaching that enables $\mathrm{CP}$ in schools to flourish requires a growth-oriented view of professional learning and development. This was reinforced in both cases; coaching was neither a compliance endeavour nor restricted to teachers deemed 'struggling'. Additionally, teachers understood the pedagogic 'why' and 'how' underpinning the focus of contextual coaching which led to greater buy-in, engagement and commitment. Whereas one-to-one confidential coaching conversations were at the heart of the joint work and mutual dialogue, network meetings (Case 1) and coaches' breakfasts (Case 2) helped to build confidence, competence and a shared language. These opportunities built internal capacity in coaching and extended the learning from coaching partners into their school community, enabling more teachers to have voice, knowledge and agency-key elements in CP.

\section{Teacher autonomy and leadership}

Positive individuality which 'diversifies and celebrates many individual and collective accomplishments together' (Hargreaves and O’Connor, 2018, p. 108) is essential to CP. Effective peer coaching can also build a collective and distributed model of leadership and professional development practice (van Nieuwerburgh et al., 2018). Although externally initiated, participants in both cases were given sufficient time, space, resources and agency to coconstruct ongoing coaching delivery and design. Individual teachers also set their own coaching goals based on the areas of improvement and innovation that they had identified as important for their students. LC roles allowed some teachers to further expand their coaching repertoire, engagement and confidence, which was significant for career development and helped to further embed the contextual coaching. 


\section{Long-term commitment and resources}

Meaningful professional learning and CP take time to develop in schools (Campbell 2017; Fullan and Hargreaves, 2016; Hargreaves and O’Connor, 2018). Likewise, learning to be an effective coach and use dialogue constructively and genuinely takes time and practice (Hollweck, 2019a; van Nieuwerburgh and Love, 2020). Whereas coaching in Case 1 had a fixed duration due to DfE funding, Case 2 showed the impact of mature contextual coaching over a period of 10 years. When contextual coaching is well resourced, deliberately designed and sustained in the long term, it has the power to enhance CP and change schools and systems substantially. Additionally, as contextual coaching matures, there are more opportunities for it to influence the four Bs of its setting.

\section{Conclusion and implications}

This multicase study showed that contextual coaching in education fosters enhanced CP and is a legitimate practice that leads to school improvement. The two cases, from different international settings with unique contextual and cultural features, each demonstrated how contextual coaching promoted the sharing and deepening of expertise, good judgement, collective responsibility and inquiry, as well as candid, constructive and respectful dialogue. There is no one right way to do coaching in education; it can be initiated externally or internally, but a deliberate and iterative design and structure attuned to the setting and contributing to the context is critical. Although the original data were not collected in line with Hargreaves and O'Connor's (2018) CP tenets, the findings from this multicase study demonstrated that they are useful guideposts for coaching programme design and implementation. Some tenets are naturally foundational to coaching, such as mutual dialogue, joint work, collaborative inquiry and collective responsibility. Others, like collective autonomy, initiative and efficacy, emerge more 
strongly when the programme matures and builds in meaningful and sustained co-construction.

With more attention to all 10 tenets in the coaching design and ongoing adaptation, common meaning and purpose, big picture thinking for all and collaborating with students may also be strengthened. These indicate opportunities to further increase the school improvement impact of contextual coaching. Acknowledging the limitations of this research, including the use of only two cases, further research which directly gathers data related to $\mathrm{CP}$ and contextual coaching would be useful. Ultimately, this study shows contextual coaching offers promising potential for policy makers, school leaders and practitioners interested in fostering school improvement.

\section{References}

Adams, M. (2015), Coaching Psychology in Schools: Enhancing Performance, Development and Wellbeing, Routledge, Abingdon, UK.

Aguilar, E. (2020), Coaching for Equity: Conversations That Change Practice, John Wiley \& Sons, New York, NY.

Bachkirova, T., Cox, E. and Clutterbuck, D. (2014), "Introduction”, In E.Cox, T. Bachkirova and D.Clutterbuck (Eds), The Complete Handbook of Coaching (2nd edn), SAGE, London, UK.

Ball, S. (2003), “The teacher's soul and the terrors of performativity", Journal of Education Policy, Vol. 18 No. 2, pp. 215-228.

Bloom, G., Castagna, C., Moir, E. and Warren, B. (2005), Blended coaching: Skills and Strategies to Support Principal Development. Thousand Oaks, CA, Corwin Press.

Campbell, C. (2016), "Collaborative professionalism: Of, by and for Catholic school leaders", Principal Connections, Vol. 20 No. 1, pp. 6-7.

Campbell, C. (2017), "Developing teachers' professional learning: Canadian evidence and experiences in a world of educational improvement", Canadian Journal of Education/Revue canadienne de l'éducation, Vol. 40 No. 2, pp. 1-33.

Campbell, C. (2021), "Partnership working and collaborative professionalism for educational improvement in Ontario, Canada", Die deutsche Schule, Vol. 113 No. 1, pp. 74-84.

Campbell, J. and van Nieuwerburgh, C. (2018), The Leader's Guide to Coaching in Schools, Thousand Oaks, CA, Corwin Press.

Chew, A.W. (2020), "Informed guessing: enacting abductively-driven research. International Journal of Research \& Method in Education, Vol. 43 No. 2, pp. 189-200. 
Cordingley P, Higgins S, Greany T and Coe, R, (2015), Developing great teaching: Lessons from the international reviews into effective professional development, Teacher Development Trust. Available at: tdtrust.org/about/dgt (accessed 12 January 2021).

Cox, E. (2003), "The contextual imperative: Implications for coaching and mentoring", International Journal of Evidence Based Coaching and Mentoring, Vol. 1 No. 1, pp. 9-22.

Downey, M. (2003), Effective Coaching: Lessons from the Coach's Coach, Thomson-Texere, New York, NY.

Earl Rinehart, K., 2020. Abductive analysis in qualitative inquiry. Qualitative Inquiry, Vol. 27 No. 2, pp. 303-311. DOI: 10.1177/1077800420935912

Fletcher, S. J. (2012). Coaching: An overview. S. Fletcher \& C.A. Mullen (Eds.). The SAGE Handbook of Mentoring and Coaching in Education (pp. 24-40). Thousand Oaks, CA: SAGE Publications.

Fullan, M., and Hargreaves, A. (2016), Bringing the profession back in: Call to action, A Report for Learning Forward, Oxford, OH. Available at: https://learningforward.org/report/professional-learning-canada/bringing-professionback/

Gorrell, P., and Hoover, J. (2009), The Coaching Connection: A Manager's Guide to Developing Individual Potential in the Context of the Organization, American Management Association, New York.

Grant, A.M. (2013), "The efficacy of coaching", Passmore, J., Peterson, D., and Freire, T. (Eds), The Wiley-Blackwell Handbook of the Psychology of Coaching and Mentoring, John Wiley \& Sons, Ltd., New York, NY, pp.15-39.

Grant, A. and O'Connor, S. (2019), "A brief primer for those new to coaching research and evidence-based practice", The Coaching Psychologist, Vol. 15, No.1. pp. 3-10.

Greany, T., and Higham, R. (2018), Hierarchy, markets and networks: Analysing the 'selfimproving school-led system' agenda in England and the implications for schools, UCL Institute of Education Press, England, UK.

Gregory, B. T., Harris, S. G., Armenakis, A. A., and Shook, C. L. (2009), "Organizational culture and effectiveness: A study of values, attitudes and organizational outcomes", Journal of Business Research, Vol. 62, No.7, pp. 673-679.

Gu, Q., Rea, S., Smethem, L., Dunford, J., Varley, M., Sammons, P., Parish, N., Armstrong, P., and Powell. L. (2015), Teaching Schools Evaluation, Final Report for National College for Teaching and Leadership, England, UK. Available at: https://assets.publishing.service.gov.uk/government/uploads/system/uploads/attachment_ data/file/503333/Evaluation_of_Teaching_schools_FINAL_FOR_PUB_25_feb_final_.pd $\mathrm{f}$

Hargreaves, A. (2019), "Teacher collaboration: 30 years of research on its nature, forms, limitations and effects", Teachers and Teaching, Vol. 25 No. 5, pp.6 03-621. 
Hargreaves, A. and Fullan, M. (2015), Professional Capital: Transforming Teaching in Every School, Teachers College Press, New York, NY.

Hargreaves, A. and O'Connor, M.T. (2018), Collaborative Professionalism: When Teaching Together Means Learning for All, Corwin Press, Thousand Oaks, CA.

Hargreaves, A., and Skerrett, A. (2008), "Engaging policy: Neither a borrower nor a lender be", European Training Foundation Yearbook, Vol. 45, pp. 913-945.

Harris, A., Adams, D., Jones, M.S. and Muniandy, V. (2015), "System effectiveness and improvement: The importance of theory and context", School Effectiveness and School Improvement, Vol. 26 No. 1, pp. 1-3, DOI: 10.1080/09243453.2014.987980

Hollweck, T. (2017), "Threading the needle: examining the teacher induction program (TIP) in the WQSB" in Kutsyuruba, B, and Walker, K (Eds.). The Bliss and Blisters of Early Career Teaching: A Pan-Canadian Perspective, Word \& Deed Publishing Incorporated, Ontario, pp. 205-226.

Hollweck, T. (2019a), “I love this stuff!': A Canadian case study of mentor-coach wellbeing." International Journal for Mentoring and Coaching in Education, Vol. 8 No. 4, pp. 325-344. https://doi.org/10.1108/IJMCE-02-2019-0036

Hollweck, T. (2019b), A Patchwork Quilt: Examining mentoring, coaching, and teacher induction in the Western Quebec School Board. PhD Thesis. University of Ottawa Available at: https://ruor.uottawa.ca/handle/10393/39919?mode=full

Hollweck, T (2020), "Peer coaching." Principal Connections: The Magazine of Catholic Principals Council/Ontario, Vol. 24 No. 2, p. 50-52

Jarvis, R., Dempsey, K., Gutierrez, G., Lewis, D., Rouleau, K., and Stone, B. (2017), Peer Coaching that Works: The Power of Reflection and Feedback in Teacher Triad Teams, McREL International, Denver, CO. Available at: https://files.eric.ed.gov/fulltext/ED588635.pdf

Johns, G. (2006), "The essential impact of context on organizational behavior", Academy of Management Review, Vol. 31 No. 2, pp. 386-408.

Johnson, S.M., Kraft, M.A., and Papay, J.P. (2012), "How context matters in high-need schools: The effects of teachers' working conditions on their professional satisfaction and their students' achievement", Teachers College Record, Vol. 114 No. 10, pp. 1-39

Knight, J., (2017), The Impact Cycle: What Instructional Coaches Should Do to Foster Powerful Improvements in Teaching, Corwin Press, Thousand Oaks, CA.

Knight, J. (2015), Better Conversations: Coaching Ourselves and Each Other to be More Credible, Caring, and Connected, Corwin Press, Thousand Oaks, CA.

Kraft, M.A. and Blazar, D. (2017), "Individualized coaching to improve teacher practice across grades and subjects: New experimental evidence", Educational Policy, Vol. 31 No. 7, pp. 1033-1068.

Kraft, M.A., Blazar, D. and Hogan, D. (2018), "The effect of teacher coaching on instruction and achievement: A meta-analysis of the causal evidence", Review of Educational Research, Vol. 88 No. 4, pp. 547-588. 
Kraft, M.A., Marinell, W.H, Shen-Wei Yee, D. (2016), "School organizational contexts, teacher turnover, and student achievement: Evidence from panel data", American Educational Research Journal, Vol. 53 No. 4, pp. 1411-1499.

Laing, K. and Todd, L. eds. (2015), "Theory-based Methodology: Using theories of change in educational development, research and evaluation", Research Centre for Learning and Teaching, Newcastle University. Available at: https://www.ncl.ac.uk/media/wwwnclacuk/cflat/files/theory-based-methodology.pdf

Lofthouse, R. (2019), "Coaching in education: A professional development process in formation", Professional Development in Education, Vol. 45 No. 1, pp. 33-45.

Lofthouse, R. (2018), "Talking about our work as educators; Stress release or active engagement?”, CollectivED blog post, 8 November. Available at: https://www.leedsbeckett.ac.uk/blogs/carnegie-education/2018/11/talking-about-ourwork-as-educators-stress-release-or-active-engagement/

Lofthouse, R., and Leat, D. (2014), "An activity theory perspective on peer coaching", International Journal of Mentoring and Coaching in Education, Vol. 2 No. 1, pp. 8-20. https://doi.org/10.1108/20466851311323050

Lofthouse, R., and Rose, A. (2019), Evaluation of the Metacognition in Service Schools SSIF Initiative: An end of project report for the Swaledale Teaching Alliance, Project Report. Available at: https://www.leedsbeckett.ac.uk/-/media/files/schools/school-ofeducation/swaledale-ssif-project-evaluation-metacognition-in-maths.pdf?la=en

Lofthouse, R., and Thomas, U. (2015), "Concerning collaboration; teachers' perspectives on working in partnerships to develop teaching practices", Professional Development in Education, Vol. 43 No. 1, pp. 36-56.

Mezirow, J. (2009), “An overview on transformative learning”, Illeris, K. (Ed.), Contemporary Theories of Learning, Routledge, Abingdon, UK, pp.90-105.

Moir, E., and Bloom, G. (2003), "Fostering leadership through mentoring", Educational Leadership, Vol.60 No.8, pp. 58-60.

Mullen, C. A. (2012), "Mentoring: An overview. S. Fletcher and Mullen, C.A. (Eds.), The Sage Handbook of Mentoring and Coaching in Education, Thousand Oaks, CA: Sage Publications, pp. 7-23.

Munro, C. (2017), "Context, context, context: implementing coaching in schools", Education Today, pp. 38-40. Available at: https://www.growthcoaching.com.au/articlesnew/context-context-context-implementing-coaching-in-schools

Paterson, C. and Munro, C. (2019), "Coaching for a Culture of Thinking", Australian Educational Leader, Vol. 41 No. 3, p.47.

Proffitt, C (2020), "Coaching to Empower a Culture of Autonomy", A practice insight working paper, CollectivED, Vol. 11, pp. 63-67. Available at: https://www.leedsbeckett.ac.uk//media/files/research/collectived/collectived-issue-11-final3.pdf

Quigley, A., Muijs, D., and Stringer, E. (2018), Metacognition and self-regulated learning: Guidance Report, Education Endowment Foundation, UK. Available at: 
https://educationendowmentfoundation.org.uk/public/files/Publications/Metacognition/E EF_Metacognition_and_self-regulated_learning.pdf

Ritchie, J. and Spencer, L. (1994), "Qualitative data analysis for applied policy research", in Bryman, A., and Burgess, R. G. (Eds.), Analyzing Qualitative Data, Routledge, New York, NY, pp. 173- 194.

Rhodes, C. and Beneicke, S. (2003), "Professional development support for poorly performing teachers: challenges and opportunities for school managers in addressing teacher learning needs", Journal of In-Service Education, Vol. 29 No. 1, pp. 123-140.

Saldaña, J. (2015), The Coding Manual for Qualitative Researchers, Sage Publications, Thousand Oaks, CA.

Sharratt, L. (2016), "Setting the table for collaborative professionalism", Principal Connections, Vol. 20 No. 1, pp. 34-37.

Stake, R. E. (2013), Multiple Case Study Analysis. Guilford press, New York, NY.

Tavory, I., and Timmermans, S. (2014), Abductive Analysis: Theorizing Qualitative Research, The University of Chicago Press, Chicago, IL.

Timmermans, S. and Tavory, I. (2012), "Theory construction in qualitative research: From grounded theory to abductive analysis", Sociological Theory, Vol. 30 No. 3, pp. 167-186.

Timperley, H., Kaser, L., and Halbert, J. (2014), A framework for transformational learning in schools: Innovation and the spiral of inquiry, Centre for Strategic Education, Vol. 234, Melbourne, Australia.

Valentine, M. (2019), "Contextual coaching: Leveraging context for alignment in the system, Philosophy of Coaching: An International Journal, Vol. 4 No. 1, pp. 93-106. ttp://dx.doi.org/10.22316/poc/04.1.07

van Nieuwerburgh, C. (ed.) (2018), Coaching in Education: Getting Better Results for Students, Educators, and Parents, Routledge, Abingdon, UK.

van Nieuwerburgh, C., Knight, J., Campbell, J. (2018), "Coaching in Education" in Susan English, O.S.B., Sabatine, J.M. and Brownell, P. (eds.), Professional Coaching: Principles and Practice, Springer Publishing Company, Switzerland.

van Nieuwerburgh, C. and Love, D. (2019), Advanced Coaching Practice: Inspiring Change in Others. SAGE Publications Limited, London, UK.

Whitmore, J. (2010), Coaching for Performance: Growing Human Potential and Purpose- the Principles and Practice of Coaching and Leadership, $4^{\text {th }}$ Ed, Nicholas Brealey, London, UK.

Yin, R. (2014), Case Study Research: Design and Methods, SAGE Publications, Thousand Oaks, CA. 